\title{
EXPLORING THE ORGANIZATIONAL CULTURE OF HIGHER EDUCATION INSTITUTIONS IN VIETNAM FROM FACULTY'S PERSPECTIVE - A CASE STUDY
}

\author{
Nguyen Hoang Thien ${ }^{\mathrm{a}}$ \\ Ho Chi Minh City University of Education
}

\begin{abstract}
This research aims to explore the nature of organizational culture in the context of the higher education sector in Vietnam. This study hopes to enrich literature on organizational culture, the organizational culture of higher education institutions, and relevant themes in the context of Vietnam. In this research, qualitative methods and a single-case holistic type are chosen to help fulfill the purposes of this study. The findings show that in higher education institutions in Vietnam, morality, professional knowledge, and the teaching methodologies of faculty are the most important values. Additionally, hierarchical order and university rules and decisions should be respected, and faculty members are believed to be role models for students. There is also the emergence of the elements of relationships, salary, and promotion as important components of culture.
\end{abstract}

Keywords: Organizational culture, higher education institutions in Vietnam, teacher training, cultural dimensions, levels of organizational culture

\section{Introduction}

It is essential to understand organizational culture when investigating organizational life (Cameron \& Quinn, 1999). This is because culture is the single largest factor that can hinder the development and change of an organization (Gwaltney, 2013). Empirical evidence also suggests that organizational culture has a strong impact on employee attitudes and organizational effectiveness (Gregory et al., 2009). In the domain of higher education, Tierney (1988) claimed that investigating the culture of higher education institutions "equips us to understand and, hopefully, reduce adversarial relationships" (p. 5). In the 1960s, research on the organizational culture of higher education institutions increased with the emergence of large research projects focusing on it (Clark, 1963; Clark \& Trow, 1966). However, the study of the organizational culture of universities in particular and the culture of organizations in general only truly became prominent at the end of the 1980s, when it gained the attention of many researchers and various research works on the subject were introduced (Allaire \& Firsirotu, 1984; Barley et al., 1988; Denison, 1990).

The higher education system in Vietnam currently has four levels: college, undergraduate, master, and doctorate (World Bank, 2005). Higher education in Vietnam is provided by universities, colleges and academic research institutes. There are different kinds of universities in Vietnam such as technical universities, agricultural universities, and medical universities. Colleges (called Cao Dang in Vietnamese) are those that offer three-year training programs, while universities offer four-to-sixyear undergraduate programs, and some also have masters and doctorate programs (Nuffic, 2015). In the 2017-2018 academic year, Vietnam had 235 universities (not including those in the security and defense sectors), 170 of which were public institutes and 65 of which were non-public institutes (The Ministry of Education and Training, 2019).

a Correspondence can be directed to: hoangthien@ier.edu.vn 
As a whole, Vietnam's higher education has a long history with many marked changes caused by national strategies and external impacts. As a consequence of foreign influences, traditional Vietnamese higher education institutions are still "heavily influenced by the 'ivory-tower' education from the ancient Chinese, the 'academic' education from the French and the strong research oriented higher education from the former Soviet Union" (Pham, 2001, p. 55). Also, it is worth noting that although Vietnam has been greatly influenced by foreign factors, it is very distinctive in its culture, traditions, and beliefs (Borton, 2000).

Vietnamese higher education institutions are not given much freedom and are state controlled. As Dao and Hayden (2015) indicated, "in Vietnam, public universities and colleges are not generally able to make their own decisions, especially about matters that are fundamentally important to them as academic communities" (p. 323). Important fields in public institutions (except for the two national universities - Vietnam National University in Hanoi and Vietnam National University in Ho Chi Minh City), such as training programs, curriculum frameworks, enrollment quotas, expenditure norms, and capital expenditure, are still made by the state. However, now there are 23 public higher education institutions that have been given autonomy under a pilot program begun in 2015. This means that these institutions are allowed to make their own decisions, but their tuition fees cannot exceed the ceilings imposed by the government (Vo \& Laking, 2020). Similarly, non-public higher education institutions are also bonded to many of these rules to a very high extent (Hayden \& Lam, 2010). When it comes to administrative systems, with the exception of the two national universities and a few leading institutes supervised directly by the Prime Minister's Office, most higher education institutions are controlled by different ministries, mainly the Ministry of Education and Training, as well as by state instrumentalities, including state corporations and in many cases provincial governments, mainly the Ministry of Education and Training. These ministries and state instrumentalities advise the government about national policy formulation, national target setting, and financing for higher education (Hayden \& Lam, 2007).

In investigating the governance of Vietnamese higher education, Dao and Hayden (2010), Dao (2009), and Pham (2010) identified cultural aspects related to the rector of a university in Vietnam, who is believed to have a decisive role in almost all of the university's activities, including "developing the long-term academic plan for the institution, establishing regulations for the institution's organization and performance, creating academic structures, managing the budget, providing training and development for academic staff and allocating academic titles" (Dao, 2009, p. 48). In higher education institutions, the power of rectors "will remain forever circumscribed by Communist Party policies and processes and a state disposition to govern by means of tight regulatory control" (Pham, 2010, p. 55). Some researchers, such as Pham and Hayden (2019) and Le (2016), also mentioned the existence of "political taboos" in the Vietnamese university environment. Specifically, lecturers often have to pay attention during their teaching and research activities to whether they act with political sensitivity or not, as political censorship exists in Vietnamese universities. In general, Vietnamese higher education institutions are believed to lack connection with external stakeholders. Traditionally, it is only the government that they are accountable to since they receive annual funding from the state (Vallely \& Wilkinson, 2008). The cooperation with the private sector and foreign partners in different aspects such as research and technology commercialization and training is also limited. This is partly because of the absence of necessary facilities, flexible policies for attracting outside investment and collaboration, and a tradition of cooperation and information sharing (Spoo \& Dao, 2010). Due to the existing funding mechanism, there is also a lack of financial incentives to invest in cooperation programs in many public higher education institutions. Moreover, generally in Vietnam higher education institutions are too narrowly focused on professional training and certification, to the neglect of their other roles. It is not surprising that the public is generally disappointed in them (Pham, 2010). There is also distrust of industry in relation to intellectual property issues when having joint projects with higher education institutions (Spoo \& Dao, 2010). Le (2016), while exploring academic culture and academic identity in Vietnam's higher education system, partly showed some features of the organizational culture of Vietnamese institutions, particularly of four 
leading, research-oriented universities, with the use of Tierney's (1988) perspective on organizational culture. The study showed that although the missions of universities vary in their direction of interest in research, there is a large gap between the missions proposed and the reality of life in academic departments. Socialization is formed mainly from the work of lecturers in the faculty instead of from the influence of the university. Information flow in the selected universities is generally efficient, and the Internet is considered to be especially useful in helping faculty members stay informed. Regarding decision-making strategies, despite there being both some support and opposition, the majority of participants showed no interest in the topic. The universities chosen in the research were also said to lack an effective management system or process to recognize faculty contributions.

However, research relevant to the organizational culture of Vietnamese higher education institutions mainly investigates a few cultural aspects instead of presenting a comprehensive picture of the culture of these organizations and the researchers rarely go into depth to explain why certain cultural features exist. Additionally, although taking cultural considerations into account, some studies do not consider organizational culture as their focus, and therefore, only a few aspects of organizational culture are mentioned in passing. This study aims to take features of current research on organizational culture and relevant themes as well as the importance of understanding the culture of a higher education institution into account as it discloses what comprises the organizational culture of Vietnamese higher education institutions. The research results will help to create a better understanding of matters related to the organization and management of Vietnamese higher education and serve as a basis for stakeholders to create effective solutions to develop this sector. This study also aims to enrich the number of studies on organizational culture, the culture of higher education institutions, and relevant themes in the context of Vietnam, especially in relation to what are considered to be core values in the organizational culture of a Vietnamese public university, and more specifically, of a teacher training institution.

\section{Theoretical and Analytical Framework for Exploring Organizational Culture}

Compared with other theories about organizational culture, Schein's three-level theory (Schein, 2010) has so far been regarded as the most useful classification in which aspects of organizational culture have been put into usable groupings (Ott, 1989). Many researchers, such as Siehl and Martin (1984) and Sathe (1985), applied this theory to their projects on matters related to organizations. The use of Schein's theory is so common that it can be seen as an indication of the start of "a badly needed movement toward general agreement on a conceptual definition of organizational culture" (Ott, 1989, p. 61).

According to the model created by Schein (2010), organizational culture consists of three levels with various features, including artifacts and creations, values, and basic assumptions. Level 1 of organizational culture-artifacts-consists of the constructed physical and social environment of an organization that can be seen, heard, or felt when an individual interacts with the organization. Level 2 of organizational culture consists of shared beliefs and values. Constructs of organizational culture in level 2 include ethos, philosophies, ideologies, ethical and moral codes, attitudes, strategies, and goals that are shared by the organization's members (Ott, 1989). Level 2 is a deeper layer than level 1 in that it consists of less visible elements, which are often expressed in official philosophies of the organization and public statements made by its leaders. Level 3-basic underlying assumptions or values in use-is the deepest layer and the most important level of organizational culture. Schein (2010) defined basic assumptions as fundamental beliefs, values, and perceptions that "have become so taken for granted that one finds little variation within a cultural unit" (Schein, 2010). These implicit assumptions guide behavior and tell group members how to perceive, think about, and feel about things (Argyris \& Schon, 1974; Argyris, 1976).

This research specifically chose the framework developed by Tierney (1988) to analyze organizational culture. This framework is based on data gathered from higher education institutions entirely in the United States and has been used by various researchers when they conducted 
research on cultural issues in the context of higher education institutions, such as Bartell (2003) and Haftu (2015). There is no emphasis on conflicts or irresolvable tensions of different dimensions of organizational culture in this framework; instead, it explores this type of culture from the integration approach with the hope that it is easier for leaders to make and implement their decisions once they have a complete and accurate understanding of the organization's culture. There are six dimensions in this framework: environment, mission, socialization, information, strategy, and leadership (Tierney, 1988). According to Tierney (1988), each of these dimensions examines different core issues in an organization's culture from a variety of angles.

This research aimed to use this framework to reveal different levels of the organizational culture of Vietnamese higher education institutions. In order to examine level 1 of the six dimensions, the research used questions that can discover measurable objects, such as "What is?", "Who is?", and "How is it done?" Based on the features of organizational culture in this level as presented by Schein (2010), level 2 answers the question of "What ought to be done (communicated, explained, rationalized, and justified)?" Since level 2 explores perceptions about the activities that people are expected to do in the organization in all aspects, this level was explored in the six dimensions. Regarding level 3, basic values primarily answer the question of "How do you do (perceive, think about, and feel about) things in reality?" In addition to comparing what is regarded as beliefs and values with what really exists in the environment, this research also explored the matter of perception (Schein, 2010). To be specific, this study asked lecturers about the deeper causes of the formation and existence of their expected behavior, values, and beliefs at the university. Similarly, in discussing ways of revealing the deepest layer of organizational culture, Cameron and Freeman (1991) suggested that "underlying assumptions related to organizational culture are more likely to emerge from questions that ask respondents to react to already-constructed descriptions of organizations than from questions asking respondents to generate the descriptions themselves" ( $p$. 32). The analytical framework used in this research is illustrated in Figure 1. The dimensions in the analytical framework are divided by broken lines to reflect the blurred boundaries of the dimensions, as culture is an interconnected web of relationships (Tierney, 1988).

\section{Figure 1. Organizational Culture (Tierney, 1988)}

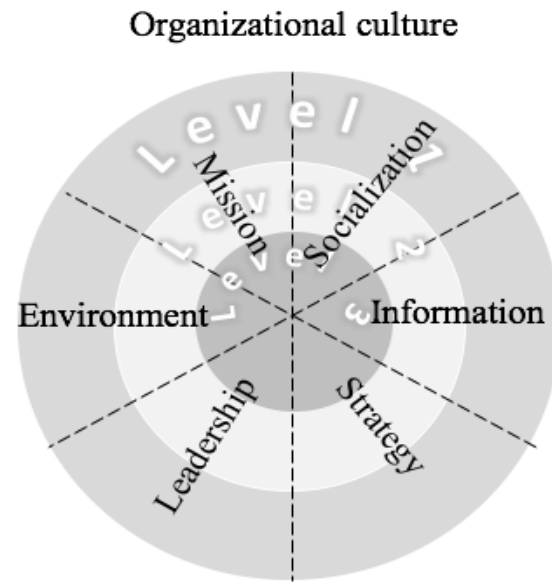

\section{Research Methodology}

\section{Research Design}

Qualitative methods were chosen for this study to explore the research topic for a number of reasons. Since this study aims to understand the ideas of individuals, it is necessary to have a wide range 
of opinions, which can be examined with less difficulty by using qualitative methods than by using quantitative methods (Tettey, 2006). Another point is that organizational culture is very complicated, and values or basic assumptions as representations of organizational culture are hard to measure. However, many scholars admitted in their qualitative analyses that these claims would be useful (Cui \& Hu, 2012). To be more specific, Schein (1990) emphasized that culture is always dynamic and includes all aspects of human functioning; therefore, he recommended using interviews and observation to understand basic assumptions, which are very abstract.

Amongst different research designs in qualitative research, in Yin's view (2014), case studies are appropriate when researchers intend to examine a phenomenon with contextual impacts or when the research problem is a phenomenon in a natural context. In addition, case studies are well suited to studies seeking personal insights into a complex phenomenon (Morse \& McEvoy, 2014). In this research, organizational culture is a phenomenon in need of investigation, the context is a specific university, and faculty's ideas about their organizational culture are collected. When taking these typical aspects of case studies and unique features of this study into account, the research found that case study research is the right choice.

\section{Case Study}

In this research, one public university in Vietnam was chosen as a case study-UE. This is a teacher training university whose main campus is located in Ho Chi Minh City, Vietnam. Currently, UE has about 1,000 staff, of which nearly 700 are faculty members. This university was selected as a case study from among more than 200 universities and colleges in Vietnam for a number of reasons. First, the selection of a public institution can represent the overall picture of higher education in Vietnam since public institutions occupy more than two-thirds of the total number of Vietnamese higher education institutions (The Ministry of Education and Training, 2019). In addition, this is a long-established university. Although its operation was licensed in 1976, the university was originally established in 1957. This means that some cultural aspects of the institution have likely been kept since then, especially given that the organization is still functioning as a teacher training institution as it was when it was established. Hence, it is possible to see many of its cultural aspects, some of which take time to form and survive (Ceauşu et al., 2017; Alvesson \& Sveningsson, 2008).

Because the case study is a teacher training institution, cultural aspects reflected by the research may not be found in other higher education institutions, as Clark (1983) indicated that lecturers describe themselves, their work, and their purposes as being influenced by disciplinary culture. Hence, ambitious generalizations of ideas gathered from faculty members of this organization to many universities need careful consideration, especially given that most higher education institutes in Vietnam are mono-disciplinary (Le \& Hayden, 2017; Hayden \& Lam, 2010).

\section{Participants}

The researcher interviewed eight faculty members of the university. All participants in this study have been working at the university for at least four years and do not hold any managerial positions. The criterion on tenure is set to ensure the interviewees can deeply understand the culture of their institute after having accessed many of its facets. Those who have management positions on the departmental level or institutional level are not selected for the research because organizational culture studies show that the view of those holding a high position in an organization about organizational culture is different from that of non-leaders. Leadership comes with power and responsibility to shape culture, while employees mainly reflect their own views on and show their behavior in that culture (Cubero, 2007; Avolio et al., 2009; Maner \& Mead, 2010; Liden et al., 2014). In addition to fulfilling the criteria established, the study also selected faculty from various departments to ensure the inclusion of the views of various faculty with different professional backgrounds as well as to see the overall impact of organizational culture. Gender ratios were also noted, but this 
is not the focus area of the topic. The research used alternative terms-the names of the groups of departments categorized by the university-to represent the participants' department names to ensure confidentiality. Details about the participants are summarized in the following table.

Table 1. Background information of the participants

\begin{tabular}{|c|c|c|c|}
\hline Interviewees & Gender & Tenure & The groups of departments \\
\hline Interviewee 1 & Female & 6 years to less than 7 years & Educational specialization \\
\hline Interviewee 2 & Female & 6 years to less than 7 years & Social sciences \\
\hline Interviewee 3 & Male & 8 years to less than 9 years & Natural sciences \\
\hline Interviewee 4 & Male & 5 years to less than 6 years & Social sciences \\
\hline Interviewee 5 & Female & 4 years to less than 5 years & Educational specialization \\
\hline Interviewee 6 & Female & 5 years to less than 6 years & Natural sciences \\
\hline Interviewee 7 & Female & 5 years to less than 6 years & Foreign languages \\
\hline Interviewee 8 & Female & 7 years to less than 8 years & Educational specialization \\
\hline
\end{tabular}

Lecturers who satisfied the established criteria were contacted via their email addresses, which are available on the university website, for permission to interview them. In the emails sent to them, information on the research topic, the purpose of the research, and other aspects related to the interview and the participant of the interview were provided. Then, those who agreed to participate in the interview were asked about the time and location that were convenient for them. Participants were given the choice of location and time for their interviews. Selected places needed to be private and silent enough so that interviewees could feel comfortable sharing information and so information could be collected and recorded accurately. These conditions also allowed the participants to listen carefully to the questions and not to be distracted during the interviews. All of the interviews were conducted face to face in Vietnamese in 2019 in rooms for lecturers on campus, and the author translated all of the recorded transcripts into English. Among the eight interviews conducted, the longest one lasted for two hours, while the shortest one lasted fifty minutes. The average time of the official interviews was one hour.

\section{Trustworthiness}

Regarding research using qualitative methods, achieving saturation is considered by many researchers as a way to increase the trustworthiness of a study (Denzin, 2012; Yin, 2014; Fusch \& Ness, 2015). According to Dworkin (2012), the number normally believed to be sufficient for a qualitative case study ranges from 5 to 50 . However, saturation does not occur within this range in all cases. There are eight interviewees in this study, which is within the range recommended by Dworkin (2012), but in fact after the seventh interview, the information provided did not show anything new compared with that in the previous interviews. It is probable that information reached the saturation level. Nonetheless, as one of the characteristics of qualitative methods, it is possible that unreachable participants can provide new information. Therefore, the information provided should be understood in a certain context and with the view that many organizations "can more correctly be viewed in terms of multiple, cross-cutting cultural contexts changing through time, rather than as a stable, bounded, homogenous culture" (Gregory, 1983, p. 365).

The use of member checking is another way to increase the trustworthiness of a study (Creswell \& Miller, 2000). In this research, after the data analysis was completed, the author shared the transcript, coding, interpreted information, and translation from Vietnamese into English with the participants to receive comments and feedback on them. This research also designed and used a 
protocol (interview schedule) for the interview to help the author follow the same process in each interview and use well-designed questions for the right audience, which ensures the consistency of the research (Russell et al., 2011). Apart from that, the researcher spent a prolonged time in the field to make sure that data gathered were trustworthy, as Creswell and Miller (2000) recommended. Specifically, the participants were asked to spare enough time to thoroughly explore various aspects of the topic in the interviews. After that, the author kept in touch with the interviewees and continued to exchange information if necessary.

\section{Findings}

To perform thematic analysis, researchers often use two approaches, including the deductive and inductive approaches (Fereday \& Muir-Cochrane, 2006). The first approach relies on a literature review to prioritize themes before the analysis begins, while the latter refers to finding themes that emerge during and after data analysis. In this study, based on the literature review and the analytical framework, six major themes were created that correspond to the six dimensions of the organizational culture of a university. Though starting from these themes, the research also looked for new themes or sub-themes that might emerge during and after the analysis. In addition to utilizing constant comparison analyses, the research conducted negative case analyses if there were any contradictions in order to ensure the trustworthiness of the data gathered, as suggested by Lincoln and Guba (1985).

\section{Environment}

\section{Level 1}

All of the interviewees believed that the university has an "ideal geographical position". To be specific, it has "commercial, cultural and academic values as a miniature learning center of the city" (Interviewee 2), or it exists in "an educational hub" (Interviewee 8). Hence, Interviewee 2 thought "this is an ideal environment for educational activities."

\section{Level 2 and 3}

Working in the environment with these features, the organization members always pay attention to their behavior and costume even though the university does not have uniform rules for its staff members. Specifically, in an educational environment, the university faculty try to form a "habit" of having appropriate and "exemplary" behavior. Apart from that, reality shows that most faculty and staff members dress politely and formally, "including security men and cleaners. They also have good behavior. This is different from private institutions where everything seems to be 'freer" (Interviewee 2).

The lecturers working in this environment are required to enhance their academic abilities, as there is competition with nearby institutions (all interviewees). Professional knowledge, teaching methodologies, and the morality of the faculty members must especially be placed on top because lecturers are examples to students and will be models for many pupils and high school students in the future (Interviewee 1, Interviewee 2, Interviewee 3, and Interviewee 4). All interviewees also said that in reality they also have these values, beliefs, and attitudes, giving responses such as "I care about students; hence, I try to improve my teaching methodologies," (Interviewee 6) "I have striven to improve my professional knowledge," (Interviewee 4), "I try to behave politely" (Interviewee 5), "as lecturers and especially those of a teacher training university, faculty members are always 'serious,' and 'exemplary.' Geographical position does not matter," (Interviewee 1) and "whatever the environment is, the lecturers must pay attention to standards of conduct. . . That is the most important thing" (Interviewee 4). 


\section{Mission}

Level 1

In general, the interviewees thought that the mission is long and hard to remember (Interviewee 1, Interviewee 2, Interviewee 3, Interviewee 4, and Interviewee 8). After being reminded of the mission, they thought that the mission is not very realistic and too ambiguous with some big words such as "training high-quality teachers." According to these interviewees, everyone does not seem to understand what such words mean.

As shared by the majority of the interviewees, the mission has not been widely and deeply disseminated to many organization members (Interviewee 2, Interviewee 4, Interviewee 5, Interviewee 6, Interviewee 7, and Interviewee 8).

All of the participants found that the mission is a basis for some university decisions, but at the same time, they did not see the link between the mission with some other decisions. The fact that decisions and the mission do not match or support each other may relate to the fact that "some policies are issued based on the guidelines from the Ministry of Education and Training for all of the institutions across the country" (Interviewee 2).

\section{Level 2 and 3}

Concerning this dimension, all participants asserted that they have to comply with the university's mission and decisions made by the university. Even if they have opinions that are different from what the university has issued, they still have to follow the university's stance because it is their duty.

Other actions are also expected of them. Specifically, according to Interviewee 2, Interviewee 3, Interviewee 7, and Interviewee 8, lecturers need to improve their professional knowledge, teaching methods, and morality.

The lecturers must be good examples in terms of morality for students all the time. They also must try to develop their professional skills and knowledge. This is especially true because this is a teacher training university, so the lecturers must have good teaching skills. When it comes to academic research, there are other institutions better known for that. (Interviewee 2)

In my opinion, there are two things the university lecturers must do. The first thing is to develop their teaching skills so that the teaching is of high quality. The other thing is that they need to better their expertise. (Interviewee 8)

All interviewees thought they must adhere to university decisions because it is natural that the faculty members obey everything that is issued from the university, "whatever it is" (Interviewee 7). Furthermore, they are expected to develop their expertise, teaching methodologies, and morality because these elements are associated with the word "lecturers," especially lecturers of a teacher training institution (Interviewee 4, Interviewee 7, and Interviewee 8). All of the interviewees also said that, in reality, they themselves always keep improving their professional knowledge and teaching methodologies through various activities and pay attention to their behavior towards students and colleagues.

\section{Socialization}

Level 1

As shared by many lecturers, there is no guidance on this matter for new people provided by the university. Instead, it is believed to be departments' responsibility (Interviewee 1, Interviewee 2, 
Interviewee 5, Interviewee 6, Interviewee 7, and Interviewee 8) and there may be disparities among departments in this aspect (all of the interviewees).

\title{
Level 2 and 3
}

In order to socialize with people in this environment, all interviewees said that newcomers must finish their assigned tasks, comply with the university regulations and decisions, and proactively find out information about their department, their peers, and the university (Interviewee 2). They also need to be "respectful and polite to others while working with them" (Interviewee 4). These activities are to help newcomers establish "relationships" with others, which is one of the requirements for successful socialization within the workplace. The faculty members of the institution also need to improve their expertise and teaching methodologies (Interviewee 5, Interviewee 6, and Interviewee 8).

All of the interviewees assumed that they have and should have such attitudes, beliefs, and values because these feature lecturers of a teacher training institution always paying attention to their morality, professional knowledge, and teaching methodologies.

\begin{abstract}
Morality is very important. This is because in contrast to many other higher education institutions, our university - a teacher training university -is always expected to have lecturers who care about morality. In the Vietnamese's thinking, the word "teachers" has many moral implications. In addition to expertise, teachers should have appropriate ways of behavior with colleagues, with the surrounding community, and especially with students. Being "the teachers of future teachers," faculty of this institution are assumed and required to have these features. (Interviewee 4)
\end{abstract}

In addition, one of the underlying reasons for the formation and presence of these features is that lecturers of this institution respect hierarchy, which includes respect for those who have worked for longer and have a higher position (Interviewee 1, Interviewee 4, Interviewee 6, and Interviewee 8). This explains why new faculty members are required to actively communicate with and respect other peers inside and outside their department. As for compliance with the university's decisions, all of the interviewees saw it as a matter of fact which they themselves also follow: "Usually, faculty have no choice but to abide by the decisions of the university because a decision is like 'the law of the King'" (Interviewee 5).

\section{Information}

\section{Level 1}

The participants can find information sent to their personal email addresses by their departments, the university Facebook, their work account, and the university website. There is also word-ofmouth communication such as direct guidance from leaders and information shared by "a little bird" whose name is not publicly and directly mentioned (Interviewee 2, Interviewee 4, Interviewee 5, Interviewee 6, and Interviewee 7). Information from "a little bird" is shared by different individuals and information seekers normally have to actively ask for it. As per Interviewee 7, sharing information in this way is no less popular than in official or formal ways.

All interviewees said that the first holders of these formal sources of information are the university leaders, the deans and vice deans of departments, and the heads and vice heads of administrative sections. These individuals will decide on the extent of information that will be shared with lecturers and staff. Another fact is that since information is mainly disseminated in a top-down manner, there may be some information unavailable to faculty when the person in charge of disseminating information forgets to share it. 
The university hardly ever shares information with the outsiders (all of the interviewees), but "only related to the intake, my university has information sent to the press" (Interviewee 2). For some other activities, "if the university leaders contact journalists to promote important affairs, the information is shared with external stakeholders. Normally, it is not" (Interviewee 2).

\section{Level 2 and 3}

After receiving information, the university lecturers have to do what is mentioned and prioritize urgent tasks if the information is related to them.

Some lecturers, such as Interviewee 1 and Interviewee 8 , think that they have to analyze information quickly because the transmission of information is hasty.

Most of the tasks are very urgent in terms of deadline. Today, they [the leaders] give me the information, but I have to complete the assigned task tomorrow. There is no time for careful preparation. ... I have to adhere to this culture. (Interviewee 1)

The interviewees thought that the lecturers of the selected university have and should have such behavior, beliefs, and attitudes in their organization since they comply with what is issued from the university. This is why they have to consider everything carefully and try to complete everything that is assigned to them. In cases where they urgently need to raise their opinions, they must communicate their opinions to their department first out of respect for the hierarchy.

\section{Strategy}

\section{Level 1}

All participants believed that the rector and the deputy rector (the university leaders) are the decision-makers and they have the highest authorities as well. Almost all of the decisions must have their approval. They also agreed that the deans and vice deans of departments and the heads and vice heads of administrative sections are also involved in decision-making activities.

Some faculty members had no ideas about how decisions are formulated (Interviewee 1 and Interviewee 4) while some argued that decisions at their university are generally made in two ways (Interviewee 2, Interviewee 3, Interviewee 6, Interviewee 7, and Interviewee 8). According to these interviewees, the majority of decisions are made directly from the university leaders while some are based on ideas proposed by departments and/or administrative sections. The latter way is usually used when matters are specific to a department or a section.

\section{Level 2 and 3}

All interviewees thought the lecturers of their university are expected to strictly and even enthusiastically adhere to university decisions, even if they are not rational: "In cases where the provision of information is late, we still have to try our best to meet the deadline" (Interviewee 8).

If lecturers have ideas, it is also possible for them to share them, "but in general, the culture of the university does not expect or encourage lecturers to make comments" (Interviewee 1). The university leaders, especially, are not usually receptive to dissenting opinions. Lecturers are considered "offenders" or even "rebels" if they contribute ideas contrary to those of the leaders (Interviewee 2).

All of the interviewees said that in reality, they also behave and think according to what are considered to be the expected attitudes and beliefs. This means that they comply with university decisions and rules. Moreover, five participants have never contributed suggestions for the university when it comes to matters related to decision making. This is because, in their views, as university 
faculty members, they should comply with the rules and decisions made by the university. To them, this is something natural and unquestionable. Interviewee 1 and Interviewee 4 said that this reality also explains why most decisions are made in a top-down manner.

\section{Leadership}

Level 1

Most interviewees believed that the leaders of the university must be recognized by the authority (Interviewee 2, Interviewee 3, Interviewee 4, Interviewee 5, Interviewee 7, and Interviewee 8). To be specific, the rector and the deputy rector are appointed by the Ministry of Education and Training, and other leaders are appointed by the rector.

In order to disseminate the values of the university and call for the support of the organization staff, basically the leaders communicate with staff through documents or sometimes meetings (all interviewees). Additionally, the rector and the deputy rector rely on reports from the dean and/or the vice dean of each department to understand the situation of each section and spread information through these individuals (Interviewee 2 and Interviewees 3 ). The university leaders also get information on departments from Communist Party members in charge of a certain department, not directly from faculty members (Interviewee 5).

\section{Level 2 and 3}

All of the interviewees agreed that under the current leadership, the lecturers in this institution are expected to fulfill their own tasks. They need to respect leaders as well (Interviewee 1). In addition, in cases where they need to give comments, they should behave politely (Interviewee 1). Also, they must be enthusiastic and active in their careers and must contribute to the development of the university as required by the university leaders (Interviewee 2).

Additionally, some interviewees (Interviewee 1, Interviewee 5, and Interviewee 6) said that lecturers are not encouraged to make adverse comments, and they thought that their comments are often ignored by the leaders.

I have attended a meeting for the whole staff by the university leaders only once, so I cannot make a comparison. Nonetheless, according to my senior colleagues, who have attended this kind of meeting many times and have been suggesting enhancing the quality of parking lots and laboratories, the issues raised have not been solved yet. (Interviewee 6)

As for rewarding and promotion, they are done based on the rotation rules although there are ideas against this mechanism. Individuals with a high level of seniority are rewarded and/or promoted before others regardless of the fact that these 'non-senior members' have greater performance. It is similar to raises. (Interviewee 2).

These interviewees said that lecturers should have these behaviors and beliefs, and they also display them in reality because everything at the university follows a hierarchy (Interviewee 1, Interviewee 5, and Interviewee 6). Therefore, lecturers must have respect for the leaders. In addition, lecturers must be supportive and enthusiastic about the leadership's ideas and strategies because it is their tradition to comply with what the university decides without being encouraged to contribute opinions, especially if they are contrary to those of the leadership.

In general, lecturers are expected to be observers and not hoped to be questioners. The university has no concern about whether lecturers are satisfied with the university's decisions or not. They are like orders and lecturers must obey. (Interviewee 2) 


\section{Concluding Discussion}

To sum up, the organizational culture of universities in Vietnam is made up of different dimensions, the three levels of which reflect its particular features. Concerning the environment, the university selected for this study is situated in an area that is considered an academic hub of the city. The university faculty members always try to pay attention to their dress code and behavior. They dress up and behave politely, even though the university does not have specific rules on this matter. While working in this environment, faculty believed that they must keep improving their professional knowledge, teaching methodologies, and morality. However, the requirements are not limited to the physical environment of an institution. Wherever the university is located, lecturers of public institutions in general and those of teacher training institutions in particular must always be expected to have these features.

As for the mission of the university, Tierney (1988) said that if an organization has a welldeveloped culture, its mission will be shared and understood by all of its members. In this case, the university rarely shares its mission. Its mission is also rarely emphasized by leaders at events. In addition, the mission is long and difficult for everyone to remember. Lecturers also shared the idea that some programs and decisions have no connections with the mission. This result is similar to that of Le (2016), whose research shows that there is still heterogeneity between the mission and the reality in four selected universities. With this mission and these ways of disseminating it, the interviewees believed that they are expected to abide by decisions made by the university leaders and fulfill their responsibilities.

Regarding support for the socialization of new faculty, there were some negative cases. While some participants stated that their departments offer no guidance to new faculty (Interviewee 1, Interviewee 5, Interviewee 6, Interviewee 7, and Interviewee 8), others affirmed that in their departments, lecturers are permitted and advised to observe other faculty members' classes, given some tasks which help them meet more colleagues, and guided to participate in student affairs and other activities inside and outside the department (Interviewee 2, Interviewee 3, and Interviewee 4). Additionally, in terms of professional skills, new lecturers are encouraged and supported to improve their qualifications, and experienced lecturer(s) are appointed to supervise them for a one-year probationary period (Interviewee 3). The opinions of these three trainers are not similar to the majority of the other participants but do not seem contradictory. This mainly shows that there may be disparities among departments in terms of supporting new faculty socialization while the university lacks official and comprehensive guidance on this dimension. The results of this study are similar to those revealed by Le (2016) in that they showed that the interviewees found that the university gives new faculty members no specific instructions on the factors necessary for their socialization with others in the workplace. Instead, new members must proactively socialize through working with others in their department.

When discussing information in a university, Tierney (1988) argued that if leaders share information effectively with their organization's members and if the organization has informal channels for communication, it is likely that the members of the organization will feel more attached to the organization. In this study, the participants said they are not always able to get all of the information, as there is sometimes some news that is exclusive for some relevant actors. Additionally, although informal channels exist in the organization, faculty members feel these make them confused and annoyed since they need relationships to get information from "a little bird" who is often referred to in this type of word-of-mouth information. In this reality, the expected behaviors, attitudes, and beliefs for lecturers are that they must make a careful and quick analysis of information they get, establish relationships, and possess various skills. Furthermore, faculty must implement what they are sent and/or told. In cases where they desire to share ideas with the university, they should communicate them to the dean and/or vice dean of their department. It seems that rarely sharing information with external subjects goes against the general development trend of Vietnam's higher education since over the last decade, Vietnamese higher education institutions have witnessed a slight increase in the participation of external stakeholders in certain spheres (Westerheijden et al., 
2010). However, this restriction is mainly related to the sharing of some kinds of information, such as information about the political activities of the university. (even lecturers have limited access to this kind of information.) The university still shares some information with external stakeholders, especially when it is not related to politics, like enrollment information or the university's important events. The fact that universities in Vietnam rarely share enough information with a wide range of audiences is also mentioned by Salmi \& Pham (2019), who said that even the Ministry of Education and Training seems to have no capacity to force institutions to publicly disclose all of their activities.

From the information that has been provided by the interviewees, it is clear that when it comes to the matter of strategy, the top-down approach is commonly used in the university. If strategies are given in the bottom-up direction, they usually go through different levels. This reflects the general governance culture of Vietnamese higher education, in which higher education institutions still cling to top-down management from the state in almost all fields (Hayden \& Lam, 2010). In addition, the characteristics of this decision-making method, where the power is mainly in the hands of the rector, has been reflected in many studies (Pham, 2010; Dao, 2009). According to Hayden and Lam (2010), in higher education institutions, rectors also take the role of Party Committee Secretary, and for this reason, they usually pay more attention to ideas and activities consistent with Party resolutions, while other initiatives or activities are of low priority. This reality, combined with the Confucian culture of high "power distance," in which people in higher positions of authority want their subordinates to conform, leads to the fact that "fear of change has stalled previous attempts to reform from the top down and has constricted the space available for educators to respond to local needs and innovate at the grassroots" (Pham, 2010, p. 55).

Based on the participants' opinions, in the university, those who are officially appointed are considered as leaders. They are the rector, the deputy rector, deans, and deputy deans of departments as well as the heads and vice heads of administrative sections. However, Interviewee 6 and Interviewee 1 think that the university also has informal leaders, since "the university has the traditional veneration of mentors, so it shows respect for the people who do not need to have titles but have worked at the institution for a long time and have affirmed their prestige. These individuals still have a place in the university" (Interviewee 1). While further investigation is needed to clarify this belief, it is also worth taking the ideas shared by Interviewee 2 and Interviewee 3 into consideration: "You, yourself, consider that person to be the leader. He or she is your own leader, but everyone does not think like that," (Interviewee 2) as usually, people associate leadership with positions that must be established by the authority (Interviewee 2 and Interviewee 3 ). Under this leadership, faculty are expected to have respect for leadership and be motivated and enthusiastic to contribute to the development of the institution.

In the analysis of the information provided by the participants, it was found that the university's organizational culture is reflected in all of the six selected dimensions, as well as many of their elements. As mentioned above, to recognize aspects of level 3 of organizational culture, the research selected values and beliefs that appeared in most dimensions of organizational culture provided by the participants' responses to the questions concerning how they behave, think, feel, etc., and why they act like that in reality. The following aspects are considered to be the values in use of level 3 of the university's organizational culture, called the essence of culture or cultural DNA by Schein (2010):

i. Morality, professional knowledge, and teaching methodologies of faculty members are placed on the top.

ii. Faculty members follow a hierarchical order.

iii. Faculty members comply with the university rules and decisions.

iv. Faculty members are role models for students.

These assumptions place emphasis on teacher trainers being role models, and their characteristics can be formed under the influence of many factors, including Confucian ideas, which "imbued much of the country's population with respect for intellectual tradition and certain methods of learning," (London, 2011, p. 8) and a focus on teaching rather than research (Pham, 
2013). The influence of the Soviet management model with a highlight on hierarchical order can also be seen in this organization (Salmi \& Pham, 2019). In addition, these beliefs and values, which are still held by lecturers participating in the study as core values of their university, may be related to the unique characteristics of the institution, this type of institution, or disciplinary culture, as Clark (1983) discussed. That is why a participant from a non-teacher training university, though agreeing on the existence of lecturers as role models, did not consider this as important, as Le (2016) pointed out in her research: "The golden days were at the time of our ancestors. Those times have passed. ... Now, young people cannot survive for one day by becoming a legendary model" (p. 162). The participants placing importance on teaching rather than research in their organization also reflects the tradition that most Vietnamese universities are teaching-only institutions, as mentioned by some researchers (Pham, 2013; Pham \& Hayden, 2019).

According to the participants in this research, hierarchical order involves not only the positions of individuals at the university but also the age of the university faculty and staff members. The university lecturers respect and ask for advice from older lecturers on many matters. This result is different from what Alvesson (2004) found when presenting seven features distinguishing universities from other organizations. Specifically, this researcher stated that hierarchical division almost does not exist in the university environment, where lecturers have very high autonomy. This may be because what Alvesson provided is based on information from Western institutions, whose culture tends to be dissimilar to that of Vietnamese universities.

These values in use are also considered common features of public universities in general. The difference in culture between the two types of higher education institutions is reflected in the comparisons between the behavior of lecturers in public and private settings. In particular, lecturers of public institutions are expected to pay attention to hierarchy when they communicate or work with other lecturers whose age and position are different from their own. As for lecturers in the private sector, the relationships between and the patterns of behavior towards each other are quite equal. Also, lecturers of private institutions are believed to be able to dress more "freely" and less formally than lecturers in public institutions.

Another noteworthy feature is that the belief that faculty members comply with rules and decisions made by the university also implies the assumption that faculty members are not expected to make inquiries or comments, especially when they are unfavorable toward the university's decisions: "Faculty have to obey them, cannot change them, and cannot ask leaders to change them" (Interviewee 5). In short, the concept of compliance at the university is associated with not making comments on the university's decisions and leaders' ideas, especially adverse comments.

Through the information shared by the lecturers interviewed, another new theme emerged, which is called "relationships." This is considered by all interviewees to be a typical feature in the culture of their workplace. Lecturers are expected to have relationships in terms of socialization and information if they hope for success in socializing with others and receiving timely information. Among various methods leaders use to make decisions, the use of relationships is also included as a common strategy. This can be seen through them mainly relying on the opinions of a group of people-other leaders.

Additionally, from the themes provided to investigate organizational culture, the study witnessed the emergence of the elements of salary and promotion in the dimensions of strategy and leadership. This is different from what was discussed by other studies, such as those by Szilagyi (1979), Khatri et al. (2001), Falch \& Strøm (2005), Labatmediene et al. (2007), Candle (2010), and Albaqami (2016), since these scholars placed them in the group of regulations and rules rather than organizational culture. Here, the matters concerning raises, rewards, and promotions (associated with raises) are believed to belong to the topic of organizational culture as well, because the formation of the university's regulations on these financial matters is thought to be based on the long-standing norms of the university. In addition, the fact that people are offered a raise, reward, and promotion is often based on the principle of rotation, where priority is given to "senior" members (this is part 
of "hierarchical order" - one of the basic assumptions of the university's organizational culture), which is not specified in the university's regulations but is rather a habit or tradition of the institution.

Despite the fact that this study only looks at the organizational culture of the whole university instead of going into the culture of each department or discipline, in many respects, the lecturers interviewed provided data showing the culture of their departments in relation to the university's common culture and the influence of departmental culture on lecturers' intentions to leave the university. In particular, when it comes to the dimension of socialization, the majority of the interviewees believed that the department has a major impact on the socialization of the faculty members, while the university has only minor influences. Also, the same thing is found in the leadership dimension. The leaders in the department, the dean and the vice dean, have a direct and strong influence on lecturers, while the university leaders have influence to a lesser extent.

In general, these cultural features can be found in many other public universities in Vietnam, as mentioned by different studies. The similarities of the results of this research with other related works, even those that were carried out more than 10 years ago, reflect the fact that the culture of this selected university has experienced little change over time even though Vietnam has been trying to internationalize its education. It has been preserving what are considered to be "very traditional features" of Vietnamese higher education institutions, such as placing importance on faculty members being role models, which is typical of Confucianism, and maintaining the top-down decision-making approach, which is distinctive of the Soviet model of higher education. This may be because compared to other types of higher education institutions, teacher training organizations have more strongholds against external influences during the course of their operation (Leutwyler et al., 2017). Hence, this topic is still in need of more investigation in the future to determine if there are new features in the organizational culture of Vietnamese higher education through time.

\section{Limitations}

As a limitation, the interview data of this study are gathered from only one public university in Vietnam. Hence, other studies can be broadly scaled up and directed to other university groups. While this research seeks to understand organizational culture through only faculty's perspective, cultural exploration can also be done through investigating other subjects in the university such as leaders, administrative staff and students to create a more comprehensive picture of the organizational culture of Vietnamese higher education institutions.

\section{References}

Albaqami, A. (2016). Determinants of Turnover Intention Among Faculty Members in Saudi Public Universities Unpublished Doctoral dissertation, University of Salford. University of Salford Theses and Dissertations Archive. Available at http://usir.salford.ac.uk/id/eprint/40542/ [Accessed 20 August 2018].

Allaire, Y. and Firsirotu, M. E. (1984). Theories of organizational culture. Organization Studies, 5(3), pp.193-226.

Alvesson, M. (2004). Knowledge Work and Knowledge-Intensive Firms. Oxford: Oxford University Press.

Alvesson, M. and Sveningsson, S. (2008). Changing Organizational Culture. New York: Routledge.

Argyris, C. (1976). Theories of Action that inhibit individual learning. American Psychologist, 39(1), pp.638-654.

Argyris, C. and Schon, D. A. (1974). Theory in Practice. San Francisco: Jossey Bass.

Avolio, B. J., Walumbwa, F. O. and Weber, T. J. (2009). Leadership: Current theories, research, and future directions. Annual Review of Psychology, 60, pp.421-449. doi:10.1177/0149206310393520.

Barley, S. R., Meyer, G. W. and Gash, D. C. (1988). Cultures of culture: Academics, practitioners and the pragmatics of normative control. Administrative Science Quarterly, 33(1), pp.24-60. 
Bartell, M. (2003). Internationalization of universities: A university culture-based framework. Higher Education, 45(1), pp.43-70.

Borton, L. (2000). Working in a Vietnamese voice. The Academy of Management Executive, 14(4), pp.20-29.

Cameron, K. S. and Freeman, S. J. (1991). Culture congruence, strength, and type: Relationships to effectiveness. In RW Woodman and WA Pasmore (Eds) Research in Organizational Change and Development. Greenwich, CT: JAI Press, pp.23-58.

Cameron, K. S. and Quinn, R. E. (1999). Diagnosing and Changing Organizational Culture Based on the Competing Values Framework. Reading, MA: Addison Wesley.

Candle, J. (2010). Factors Affecting Teacher Turnover in Private Secondary Schools in Wakiso District. Kampala: Makerere University.

Ceauşu, I., Murswieck, R., Kurth, B. L. and Lonescu, R. (2017). The organizational culture as a support of innovation processes. International Journal of Advanced Engineering and Management Research, 2(6), pp.2392-2403.

Clark, B. R. (1963). Faculty cultures. In T.F. Lunsford (Ed) The Study of Campus Cultures. Boulder, CO: Western Interstate Commission for Higher Education, pp.39-54.

Clark, B. R. (1983). The Higher Education System: Academic organisation in cross-national perspective. Berkeley, California: University of California Press.

Clark, B. R. and Trow, M. (1966). The organizational context. In TM Newcomb and EK Wilson (Eds) College Peer Groups. Chicago: Adline, pp.17-70.

Creswell. J. W. and Miller, D. (2000). Determining validity in qualitative inquiry. Theory into Practice, 39(3), pp.124-130.

Cubero, C. G. (2007). Situational leadership and persons with disabilities. Work: A Journal of Prevention, Assessment, and Rehabilitation. Special Issue: Workplace Issues and Placement, 29(4), pp.351-156.

Cui, X. and Hu, J. (2012). A literature review on organization culture and corporate performance. International Journal of Business Administration, 3(2), pp.28-37.

Dao, V. K. (2009). Reforming the Governance of Higher Education in Vietnam: Case studies of change at three key universities. Unpublished Doctoral dissertation, RMIT University. RMIT University Theses and Dissertations Archive. Available at https://researchbank.rmit.edu.au/eserv/ rmit:161318/Dao.pdf/ [Accessed 20 August 2018].

Dao, V. K. and Hayden, M. (2010). Reforming the governance of higher education in Vietnam. In G. Harman, M. Hayden, and T.N. Pham (Eds) Reforming Higher Education in Vietnam: Challenges and Priorities. London/New York: Springer, pp.129-142.

Dao, V. K. and Hayden, M. (2015). Higher education governance reform in Vietnam. In KM Joshi and S Paivandi (Eds), Global Higher Education: Issues in governance. Delhi: B.R. Publishing Corporation, pp.315-338.

Denison, D. R. (1990). Corporate Culture and Organizational Effectiveness. New York: Wiley.

Denzin, N. K. (2012). Triangulation 2.0. Journal of Mixed Methods Research, 6(2), pp.80-88.

Dworkin, S. L. (2012). Sample size policy for qualitative studies using in-depth interviews. Archives of Sexual Behavior, 41(6), pp.1319-1320.

Falch, T. and Strøm, B. (2005). Teacher turnover and non-pecuniary factors. Economics of Education Review, 24(6), pp.611-631.

Fereday, J. and Muir-Cochrane, E. (2006). Demonstrating rigor using thematic analysis: A hybrid approach of inductive and deductive coding and theme development. International Journal of Qualitative Methods, 5(1), pp.1-10.

Fusch, P. I. and Ness, L. R. (2015). Are we there yet? Data saturation in qualitative research. The Qualitative Report, 20(9), pp.1408-1416.

Gregory, B. T., Harris, S. G., Armenakis, A. A. and Shook, C. L. (2009). Organizational culture and effectiveness: A study of values, attitudes, and organizational outcomes. Journal of Business Research, 62(7), pp.673-679. 
Gregory, K. L. (1983). Native-view paradigms: Multiple cultures and culture conflicts in organizations. Administrative Science Quarterly, 28(3), pp.359-376.

Gwaltney, D. (2013). Do High-Performance Human Resource Practices and Organizational Culture Affect Staff Turnover in Institutions of Higher Education? Unpublished doctoral dissertation, Eastern University.

Haftu, H. G. (2015). Academic Leaders' Views of the Role of Organizational Culture in Implementing Management Innovation: The case of Bahir Dar University, Ethiopia. Unpublished Master thesis, University of Tampere. University of Tampere Theses and Dissertations Archive. Available at https://trepo.tuni.fi/handle/10024/97866 [Accessed 23 December 2018].

Hayden, M. and Lam, Q. T. (2007). Institutional autonomy for higher education in Vietnam. Higher Education Research \& Development, 26(1), pp.73-85. doi:10.1080/07294360601166828.

Hayden, M. and Lam, Q. T. (2010). Vietnam's higher education system. In G. Harman, M. Hayden and T.N. Pham (Eds) Reforming Higher Education in Vietnam: Challenges and Priorities. London/ New York: Springer, pp.15-30.

Khatri, N., Chong, T. F. and Budhwar, P. (2001). Explaining employee turnover in an Asian context. Human Resource Management Journal, 11(1), pp.54-74.

Labatmediene, L., Endriulaitiene, A. and Gustainiene, L. (2007). Individual correlates of organizational commitment and intention to leave the organization. Baltic Journal of Management, 2(2), pp.196-212.

Le, T. K. A. (2016). Developing the Academy in Vietnam: An investigation of the formation of academic identity by university lecturers in Vietnam. Unpublished Doctoral dissertation, Southern Cross University. Southern Cross University Theses and Dissertations Archive. Available at http:// epubs.scu.edu.au/cgi/viewcontent.cgi?article=1564\&context=theses [Accessed 10 June 2020].

Le, T. K. A. and Hayden, M. (2017). The road ahead for the higher education sector in Vietnam. Journal of International and Comparative Education, 6(2), pp.77-89. doi: 10.14425/jice.2017.6.2.77

Leutwyler, B., Popov, N. and Wolhuter, C. (2017). The Internationalization of Teacher Education: Different contexts, similar challenges. Paper prepared for the Annual International Conference of the Bulgarian Comparative Education Society (BCES) (15th) and the International Partner Conference of the International Research Centre (IRC), Borovets, Bulgaria

Liden, R. C., Wayne, S. J., Liao, C. and Meuser, J. D. (2014). Servant leadership and serving culture: Influence on individual and unit performance. Academy of Management Journal, 57(5), pp.14341452. doi:10.5465/amj.2013.0034.

Lincoln, Y. S. and Guba, E. G. (1985). Naturalistic Inquiry. Beverly Hills, CA: Sage Publications.

London, J.D. (Ed) (2011). Education in Vietnam. Singapore: Institute of Southeast Asian Studies.

Maner, J. K. and Mead, N. L. (2010). The essential tension between leadership and power - When leaders sacrifice group goals for the sake of self-interest. Journal of Personality and Social Psychology, 99(3), pp.482-497.

Morse, A. and McEvoy, C. D. (2014). Qualitative research in sport management: Case study as a methodological approach. The Qualitative Report, 19(31), pp.1-13.

Nuffic (2015). The Education System of Vietnam Described and Compared with the Dutch System. Available at https://www.nuffic.nl/en/publications/education-system-vietnam// [Accessed 22 July 2020].

Ott, J. S. (1989). The Organizational Culture Perspective. California: Brooks/Cole Publishing Company Pacific Grove.

Pham, L. and Hayden, M. (2019). Research in Vietnam: The experience of the humanities and social sciences. Journal of International and Comparative Education, 8(1), pp.27-40. doi: 10.14425/ jice.2019.8.1.27.

Pham, P. (2001). HE of Vietnam and its Critical Issues in Management Education. Paper presented at the International Conference on Management Education for the 21st Century-Managing in the Digital Age in Vietnam. Hanoi, Vietnam. 
Pham, T. L. (2013). Case study: The effectiveness of research and innovation management at policy and institutional levels in Vietnam. In A. Olsson and L. Meek (Eds) Effectiveness of Research and Innovation Management at Policy and Institutional Levels in Cambodia, Malaysia, Thailand and Vietnam. Paris: OECD, pp.140-162.

Pham, T. N. (2010). The higher education reform agenda: A vision for 2020. In G. Harman, M. Hayden and T.N. Pham (Eds) Reforming Higher Education in Vietnam: Challenges and priorities. London/ New York: Springer, pp.51-64.

Russell, H., Searight, H. R., Mauldin, R. K., Ratwik, S., Conboy, R. and Searight, B. K. (2011). e-Research in the social sciences: The possibilities and the reality. Journal of Social Sciences, 3(2), pp.71-80.

Salmi, J and Pham, L. (2019). Academic governance and leadership in Vietnam: Trends and challenges. Journal of International and Comparative Education, 8(2), pp.103-118. doi:10.14425/ jice.2019.8.2.103.

Sathe, V. (1985). Culture and Related Corporate Realities. Homewood, IL: Richard D. Irwin, Inc.

Schein, E. H. (1990). Organizational culture. American Psychologist, 45(2), pp.109-119.

Schein, E. H. (2010). Organizational Culture and Leadership ( $4^{\text {th }}$ ed.). San Francisco: Jossey-Bass.

Siehl, C. and Martin, J. (1984). The role of symbolic management: How can managers effectively transmit organizational culture? In J. Hunt, D. Hosking, C. Schriesheim and R. Stewart (Eds) Leaders and Managers: International Perspectives on Managerial Behavior and Leadership. Elmsford, New York: Pergamon, pp.227-39.

Spoo, R. and Dao, A. T. (2010). Intellectual Property and Vietnam's Higher Education System. In G. Harman, M. Hayden and T.N. Pham (Eds) Reforming Higher Education in Vietnam: Challenges and priorities. London/New York: Springer, pp.117-128.

Szilagyi, A. D. (1979). Keeping employee turnover under control. Personal: The Management of People at Work, 56(6), pp.42-52.

Tettey, J. W. (2006). Staff Retention in African Universities: Elements of a sustainable strategy. Available at https://documents.worldbank.org/en/publication/documents-reports/ documentdetail/164981468194359130/staff-retention-in-african-universities-elements-of-asustainable-strategy [Accessed 15 July 2018].

The Ministry of Education and Training (2019). Số liệu thống kê giáo dục đại học năm học 2017-2018 [Higher education statistics for the 2017-2018 academic year]. Available at https://moet.gov. vn/thong-ke/Pages/thong-ko-giao-duc-dai-hoc.aspx?ItemID=5877 [Accessed 10 June 2020].

Tierney, W. G. (1988). Organizational culture in higher education: Defining the essentials. Journal of Higher Education, 59(1), pp.2-21.

Vallely, T. J. and Wilkinson, B. (2008). Vietnamese Higher Education: Crisis and response. Cambridge, MA: ASH Institute, Harvard Kennedy School.

Vo, M. T. H. and Laking, R. (2020). An institutional study of autonomisation of public universities in Vietnam. Higher Education, 79(5), pp.1079-1097. doi:10.1007/s10734-019-00457-6.

Westerheijden, D. F., Cremonini, L. and Empel, R. V. (2010). Accreditation in Vietnam's higher education system. In G Harman, M Hayden and TN Pham (Eds) Reforming Higher Education in Vietnam: Challenges and priorities. London/New York: Springer, pp.183-196.

World Bank (2005). Education in Vietnam: Development history, challenges and solutions. Available at http://siteresources.worldbank.org/EDUCATION/Resources /2782001121703274255/1439264-1153425508901/Education_Vietnam_Development.pdf/ [Accessed 5 August 2018].

Yin, R. K. (2014). Case Study Research: Design and methods ( $5^{\text {th }}$ ed.). Thousand Oaks, CA: Sage Publications, Inc. 